\title{
Right-sided infective endocarditis with coronary sinus vegetation
}

\author{
Guang Song ${ }^{1}$, Jing Zhang ${ }^{1}$, Xintong Zhang ${ }^{1}$, Huan Yang ${ }^{1}$, Wanying Huang ${ }^{2}$, Ming Du ${ }^{3}$, Ke Zhou ${ }^{4}$ \\ and Weidong Ren ${ }^{1 *}$ (i)
}

\begin{abstract}
Background: Infective endocarditis (IE) is a rare disease with high mortality. Right-sided IE accounts for 5-10\% of cases of IE. The tricuspid valve is most commonly affected, oppositely in coronary sinus (CS). The diagnoses, treatments and outcomes of CS vegetation has not been summarized yet.

Case presentation: We present a 71-year-old man complained of cough and fever. Transthoracic echocardiography revealed the aneurysmal dilated CS with the band medium-echo mobile structure. A sinus venosus atrial septal defect has been detected. He had a persistent left superior vena cava which drained the right atrium via the aneurysmal dilated CS. Blood cultures were positive for Staphylococcus aureus. After intravenous antibiotic therapy, he had the symptom of dyspnea. The suspicious diagnosis is recurrent septic lung emboli which was confirmed by thoracic contrast enhanced computed tomography. The thoracotomy was performed to repair the atrial septum and remove the CS vegetation. Ten days later, the patient was discharged with only mild cough.

Conclusion: Both positive blood cultures and echocardiography are major criteria in right-sided IE with CS vegetation. Current treatment options of CS vegetation include medical therapy and surgery. The surgical strategy for CS vegetation should be individualized, due to the controversial indications and optimum time of surgery. Most people have a good prognosis after proper treatment.
\end{abstract}

Keywords: Coronary sinus, Infective endocarditis, Vegetation, Surgery, Echocardiography

\section{Background}

Infective endocarditis (IE) is a rare disease with prevalence ranging from 3 to 10 per 100,000 person-years [1]. The average age of patients with infective endocarditis are increasing from 40 shifting to 70 [2]. Due to its high mortality $(20-25 \%)$ in the past two decades, IE is now the third or fourth most common life-threatening infection syndrome $[1,3,4]$. According to its principal associated complications in different clinical scenarios, IE could be divided into several types, including the left-sided IE, right-sided IE, prosthetic valve IE, electronic devices IE, and so on. Right-sided IE accounts for 5$10 \%$ of cases of IE [5]. The tricuspid valve is most

\footnotetext{
* Correspondence: renwdcmu@163.com

${ }^{1}$ Department of Ultrasound, Shengjing Hospital of China Medical University,

Shenyang, China

Full list of author information is available at the end of the article
}

commonly affected, oppositely in coronary sinus (CS) [5]. Herein, we present the case of a 71-year-old man with right-sided IE and CS vegetation.

\section{Case presentation}

A 71-year-old previously healthy man complained of cough and fever for 1 month. At first, he was evaluated at his local hospital, where he was believed to have pneumonia. During hospitalization, he got sudden chest pain and hemoptysis which were similar as the symptoms of the pulmonary embolism. However, lower extremity doppler ultrasound didn't found any sign of thrombus. He presented to our hospital for a definite diagnosis. On day 1, his pulse

(C) The Author(s). 2018 Open Access This article is distributed under the terms of the Creative Commons Attribution 4.0 International License (http://creativecommons.org/licenses/by/4.0/), which permits unrestricted use, distribution, and reproduction in any medium, provided you give appropriate credit to the original author(s) and the source, provide a link to the Creative Commons license, and indicate if changes were made. The Creative Commons Public Domain Dedication waiver (http://creativecommons.org/publicdomain/zero/1.0/) applies to the data made available in this article, unless otherwise stated. 
rate was 106 beats/minute, blood pressure was 134/ $83 \mathrm{mmHg}$, and his temperature was $38.3{ }^{\circ} \mathrm{C}$ on examination. There were no murmurs on auscultation of the heart. Laboratory testing revealed a white blood cell count of $21,000 / \mu \mathrm{L}$ (neutrophils $74.5 \%$ ), hemoglobin of $11.5 \mathrm{~g} / \mathrm{dL}$, and platelets of $192,000 / \mu \mathrm{L}$. Also, the C-reactive protein level is $74 \mathrm{mg} / \mathrm{L}$, and erythrocyte sedimentation rate is $66 \mathrm{~mm} / \mathrm{h}$. The coagulation function is normal. The electrocardiogram showed sinus tachycardia without other abnormalities. On day 2, transthoracic echocardiography (TTE) revealed the aneurysmal dilated CS (diameter: $38 \mathrm{~mm}$ ) with the band medium-echo mobile structure in the parasternal left ventricle long-axis view (Fig. 1a; Additional file 1: Movie 1). In the modified apical 4-chamber view, the band medium-echo mobile structure $(40 \times 12 \mathrm{~mm})$ could be observed in the aneurysmal dilated CS (Fig. 1b; Additional file 2: Movie 2). A sinus venosus atrial septal defect (ASD) with bi-directional shunt has been detected near the entrance of superior vena cava in the right atrium (Fig. 2a, b, c). Part of severe tricuspid regurgitation drained into the CS (Fig. 3). The persistent left superior vena cava has been revealed in the suprasternal long axis view of aortic arch (Fig. 4). Enlarged right heart, pericardial effusion, dilated inferior vena cava may indicate dysfunctional right heart. Moderate pulmonary artery hypertension also has been revealed. On day 4, blood cultures were positive for Staphylococcus aureus which is methicillin sensitive. We highly suspect that this is IE with CS vegetation. So, he got intravenous antibiotic therapy which lasted 2 weeks during hospitalization. Cloxacillin is given by intravenous injection as $12 \mathrm{~g} /$ day in 4-6 doses. However, on day 6 , the patient had symptoms of dyspnea and chest pain. We repeated the blood cultures which were also positive. We believed these symptoms caused by recurrent septic lung emboli. Emergency thoracic contrast enhanced computed tomography was performed and revealed filling defects in the branches of the left lower pulmonary artery (Fig. 5a, b). Sinus venosus ASD has been confirmed (Fig. 6a, b). A persistent left superior vena cava drained into the right atrium through the aneurysmal dilated CS (Fig. 6c). On day 8, thoracotomy was performed (Fig. 7a). A photograph of the gross specimen showed a netlike vegetation which was removed from the CS (Fig. 7b). The vegetation was mixed with white and dark red. Histologic sectioning revealed that vegetation contained a large number of necrotic material (Fig. 7c). After surgery, his condition became stable. On day 18, the blood culture and other laboratory testing normalized. The patient was discharged with only mild cough. After he got home, he also had two-week antibiotherapy in his local hospital. Two months later, he came to the outpatient department for follow-up. He was doing well without any complications. TTE only revealed the dilated CS and pericardial effusion.

\section{Discussions and Conclusions}

Unlike the left-sided IE mainly occurred on the aorta or mitral valve, right-sided IE could involve the tricuspid valve, pulmonary valve, eustachian valve, interventricular septum, right ventricular free wall, or CS. The right-sided IE with CS vegetation, just like our case, is extremely rare. So far, we have found 7 cases describing CS vegetation (Table 1) [6-11]. There were 3 men and 4 women. Ages ranged from 23 years to 71 years; mean age $39.6 \pm$ 19.8 years. Right-sided IE usually occurs in intravenous drug abusers or patients with human immunodeficiency virus $[10,11]$, cardiac device infection,

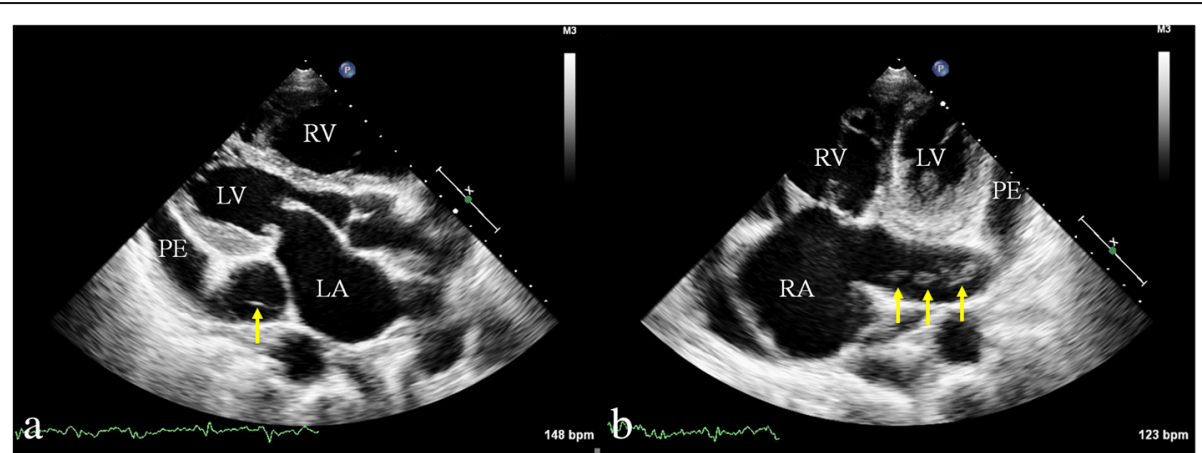

Fig. 1 The aneurysmal dilated coronary sinus with the banded medium-echo mobile structure (yellow arrow). a in the parasternal left ventricle long-axis view. b In the modified apical 4-chamber view. CS: Coronary sinus; LA: Left atrium; LV: Left ventricle; PE: Pericardial effusion; RV: Right ventricle 


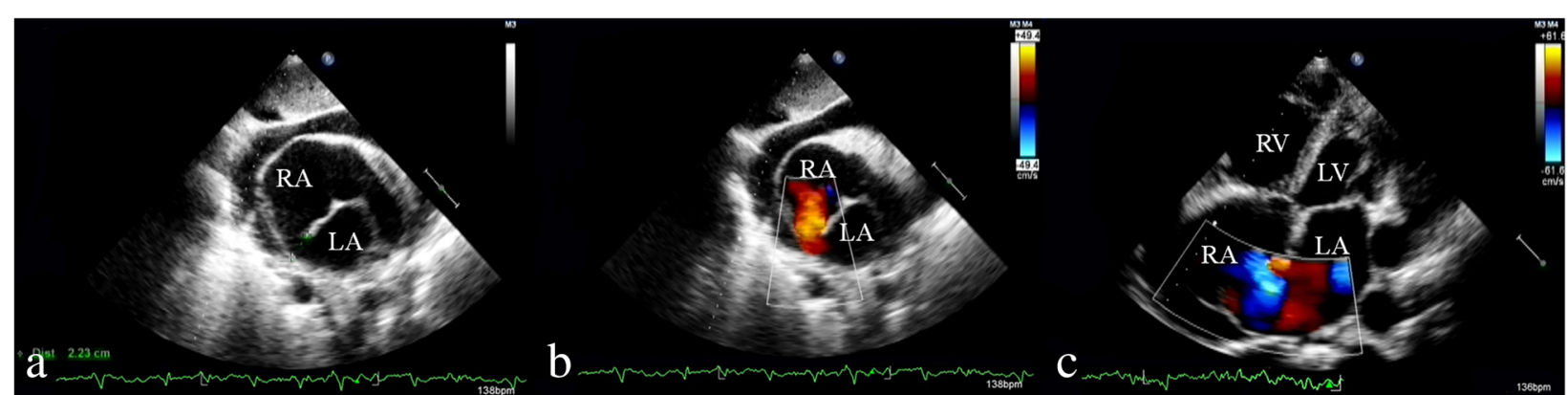

Fig. 2 Sinus venosus atrial septal defect. a The size of echo drop is $22.3 \mathrm{~mm}$. b, c bi-directional shunt has been detected between right atrium and left atrium. LA: Left atrium; LV: Left ventricle; RA: Right atrium; RV: Right ventricle

central venous catheter, congenital heart disease, and hemodialysis [8]. These risk factors may cause cardiac endothelial damage [9]. The most common symptom of these patients is fever. Due to the possibility of abscission of vegetation, right-sided IE with CS vegetation could present with a complication, particularly septic shock or pulmonary embolism (hemoptysis).

The first modality for diagnosis is TTE (71\%) and transesophageal echocardiography (29\%). Echocardiography is crucial to diagnosis. TTE is a first line imaging study in the diagnosis of IE at present [5]. In suspected IE, TTE has a moderate sensitivity (75\%) and high specificity (>90\%) in detecting IE with vegetation [12]. In patients with an equivocal or negative TTE, but high clinical likelihood of infective endocarditis, transesophageal echocardiography is necessary due to the higher sensitivity (>90\%). Each of three positive echocardiographic findings which include vegetation, cardiac abscess, and new valvular regurgitation could provide sufficient evidence of IE [13]. In particular,

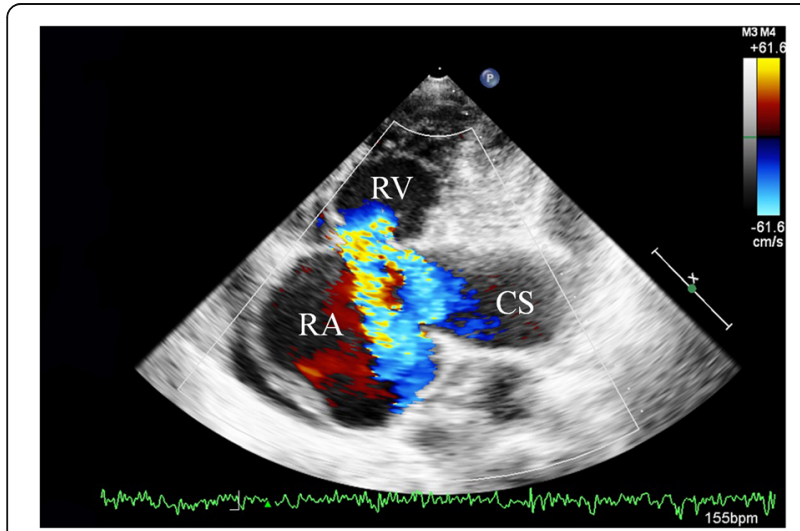

Fig. 3 Severe tricuspid regurgitation has been revealed, part of which drained into the coronary sinus. CS: Coronary sinus; RA: Right atrium; RV: Right ventricle vegetation is the landmark lesion of IE. Vegetation in the CS has some characters: First, vegetation is usually isolated, may not affect other valves. Second, the CS always dilated. Third, vegetation in the CS is usually big (length > $10 \mathrm{~mm}$ ), shaped like a tubule mass. Our case is the only netlike one. Most of CS vegetations are mobile. Echocardiography could detect of the associated cardiovascular anomalies, including coronary artery-CS fistula $[6,7,9]$, ASD, and valvular regurgitation. Echocardiography also could provide information about severity of the valve lesion, and assess the left/right ventricular function [14].

Blood culture is crucial as a major criterion for the diagnosis of right-sided IE. In these seven patients, about $71 \%(5 / 7)$ of blood cultures were positive. Pathogenic bacteria included Staphylococcus aureus (2), Streptococcus (2), and Acinetobacter baumanii (1). Similar results have been found by previous studies which revealed that Staphylococcus aureus was the most common cause of right-sided IE [15, 16]. Staphylococcus aureus infection has been shown to be an independent predictor of mortality from IE

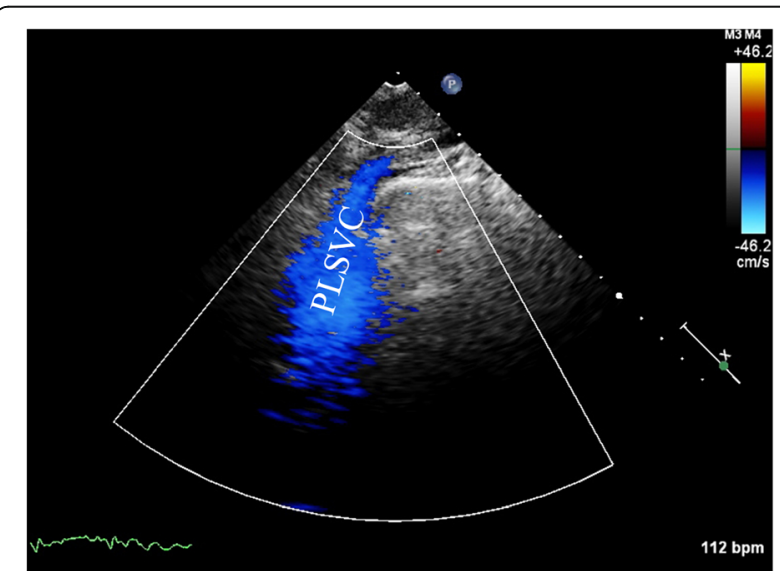

Fig. 4 The persistent left superior vena cava has been revealed in the suprasternal long axis view of aortic arch. PLSVC: Persistent left superior vena cava 


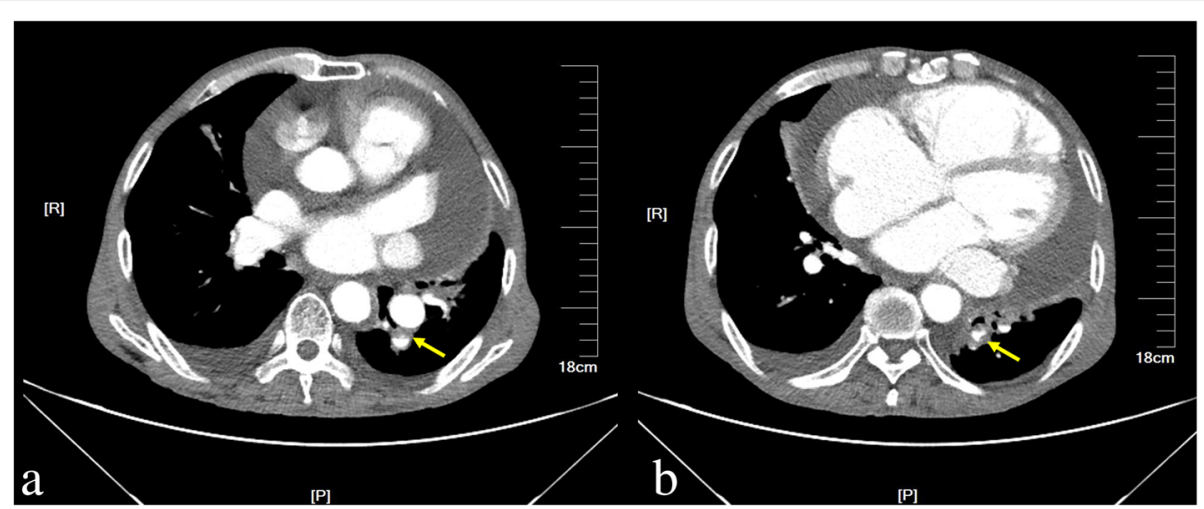

Fig. 5 Emergency thoracic contrast enhanced computed tomography revealed pulmonary embolism. $\mathbf{a}$, $\mathbf{b}$ filling defects in the branches of the left lower pulmonary artery (yellow arrow)

[17]. Doctor must pay special attention to this kind of microorganism because Staphylococcus aureus has a higher mortality (51\%) than others (31\%) [18]. The high mortality may due to its complicated large vegetations, invasive valve damage, and embolic symptom [19]. The negative result of blood culture has a incidence of $2.5-31 \%$, which could delay diagnosis and the initiation of treatment [20].

Current treatment options of IE include medical therapy and surgery. Most of the patients with CS vegetation (86\%) received antibiotic therapy. Medical therapy is the primary treatment strategy [5]. On an empirical basis, antibiotics should be started as soon as blood cultures have been acquired, but doctors could also await result of blood culture if the condition of patient is stable [14].
Treatment for at least 4-6 weeks is usually necessary. Although undertaken in $40-50 \%$ of patients with IE [3, 21 , the necessity and indications of surgery main controversial. According to previous studies and guidelines, indications for surgery of IE have been summarized [2224] (Table 2). The purpose of surgery is to eradicate the infection and achieve hemodynamic correction. The reason for surgery in our case is as follow: (1) Patients may have recurrent septic pulmonary emboli on his sixth day in hospital. (2) Patients with severe tricuspid regurgitation and dysfunctional right heart. (3) The size of vegetation larger than $10 \mathrm{~mm}$. (4) The patient has a risk of paradoxical embolism due to associating ASD with bi-directional shunt. Cerebrovascular complications, causing by paradoxical embolism, could decease the

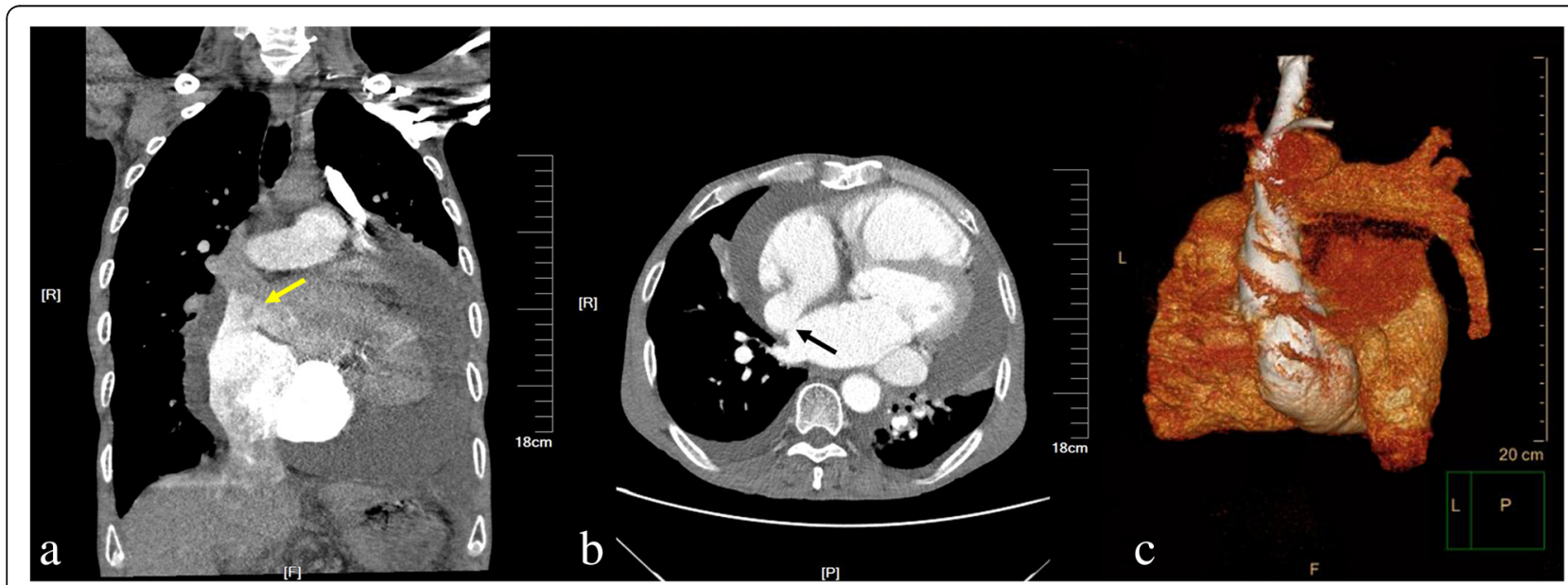

Fig. 6 Emergency thoracic contrast enhanced computed tomography revealed cardiovascular anomalies. a Contrast agent slightly appeared in left atrium (yellow arrow) when the right heart was enhancing. $\mathbf{b}$ Interruption was visible between right atrium and left atrium. $\mathbf{c} A$ persistent left superior vena cava drained into the right atrium through the aneurysmal dilated coronary sinus 


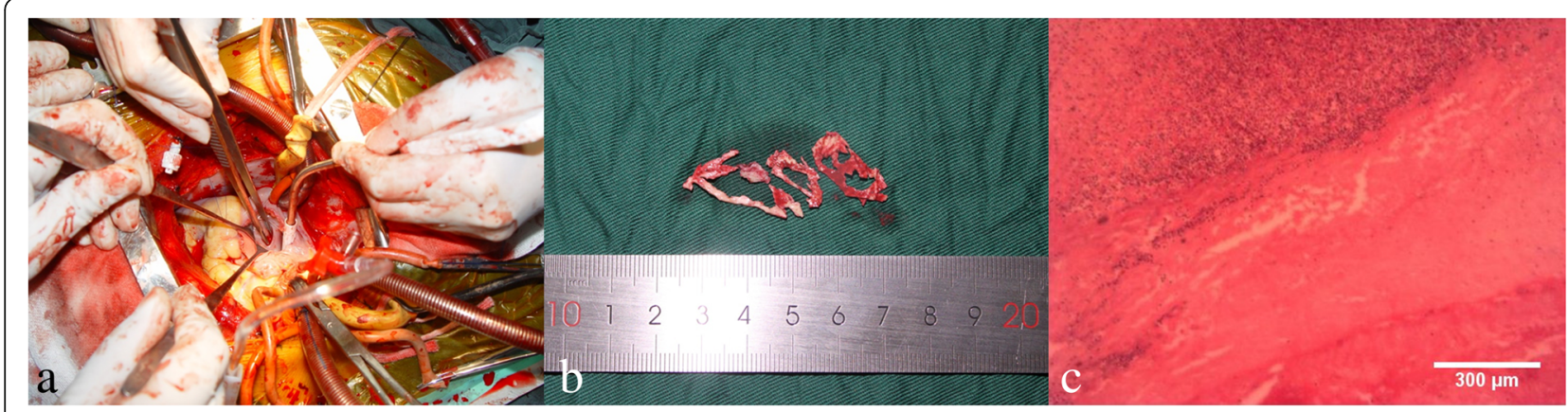

Fig. 7 a Thoracotomy was performed to repair the atrial septum and remove the coronary sinus vegetation. $\mathbf{b}$ Photograph of the gross specimen showed a netlike vegetation which was removed from the coronary sinus. The vegetation was mixed with white and dark red. c Histologic sectioning revealed that vegetation contained a large number of necrotic material and neutrophils

quality of life in the long term. The optimum time of surgery remains indistinct. Previous study revealed that early surgery should be considered early if Staphylococcus aureus is suspected [23]. Half of surgeries were performed in the acute phase, the other half in the convalescent phase [25].

Prognosis of right-sided IE is usually well. Previous study revealed the mortality of right-sided IE is $12 \%$ in-hospital patients [26], and $0-7.3 \%$ for surgical patients $[27,28]$. In these seven patients with CS vegetation, the in-hospital mortality is $14 \%$. Most of the patients have an uneventful recovery. Only one patient died due to multiple organ failure after her surgery.

Both positive blood cultures and echocardiography are major criteria in right-sided IE with CS vegetation. Current treatment options of right-sided IE include medical therapy and surgery. The surgical strategy for right-sided IE patients with CS vegetation should be individualized, due to the controversial indications and optimum time of surgery. Most people have a good prognosis after proper treatment.

Table 1 Summary of literature involving right-sided IE with CS vegetation

\begin{tabular}{|c|c|c|c|c|c|c|c|c|c|c|}
\hline No. & First Author & Year & Sex, age & Symptoms & $\begin{array}{l}\text { First } \\
\text { modality } \\
\text { for diagnosis }\end{array}$ & $\begin{array}{l}\text { Length } \times \\
\text { width of } \\
\text { vegetation }(\mathrm{mm})\end{array}$ & $\begin{array}{l}\text { Associated } \\
\text { cardiovascular } \\
\text { anomalies }\end{array}$ & Blood culture & Treatments & $\overline{\text { Outcomes }}$ \\
\hline 1 & Kasravi [6] & 2004 & M, 31y & $\begin{array}{l}\text { Fever, chills, } \\
\text { nausea, vomiting, } \\
\text { myalgias, } \\
\text { neck stiffness }\end{array}$ & TTE & $>27^{a} \times 6^{a}$ & $\begin{array}{l}\text { CACSF, } \\
\text { vegetation } \\
\text { extends to RA }\end{array}$ & $\begin{array}{l}\text { Positive for } \\
\text { Staphylococcus } \\
\text { aureus }\end{array}$ & Antibiotic & Alive \\
\hline 2 & Gill [7] & 2005 & $M, 37 y$ & Fever, weight loss & TEE & $14 \times 7$ & CACSF & $\begin{array}{l}\text { Positive for } \\
\text { Streptococcus }\end{array}$ & Antibiotic & Alive \\
\hline 3 & Kwan [8] & 2014 & $F, 23 y$ & Fever & TTE & $14 \times 2^{a}$ & $\begin{array}{l}\text { Vegetation } \\
\text { extends to RA }\end{array}$ & $\begin{array}{l}\text { Positive for } \\
\text { Acinetobacter } \\
\text { baumanii }\end{array}$ & Antibiotic & Alive \\
\hline 4 & Takashima [9] & 2016 & $F, 64 y$ & $\begin{array}{l}\text { Fever, fatigue, } \\
\text { loss of appetite, } \\
\text { septic shock }\end{array}$ & TTE & $17 \times 9^{a}$ & $\begin{array}{l}\text { CACSF, } \\
\text { vegetations on } \\
\text { the mitral and } \\
\text { aortic valves } \\
\text { with moderate } \\
\text { regurgitation, } \\
\text { heart failure }\end{array}$ & Negative & Surgery & Died \\
\hline 5 & Kumar [10] & 2017 & $F, 23 y$ & Septic shock & TEE & $30 \times 5$ & $\begin{array}{l}\text { Vegetation on the } \\
\text { Eustachian valve } \\
\text { in the RA }\end{array}$ & / & Antibiotic & Alive \\
\hline 6 & Theodoropoulos [11] & 2017 & $F, 28 y$ & $\begin{array}{l}\text { Fever, sweat } \\
\text { malaise, hemoptysis, } \\
\text { dyspnea }\end{array}$ & TTE & $15^{\mathrm{a}} \times 8^{\mathrm{a}}$ & $\begin{array}{l}\text { Tricuspid valves } \\
\text { with moderate } \\
\text { regurgitation }\end{array}$ & $\begin{array}{l}\text { Positive for } \\
\text { Streptococcus }\end{array}$ & Antibiotic & Alive \\
\hline 7 & Our case & 2017 & $M, 71 y$ & $\begin{array}{l}\text { Fever, cough, } \\
\text { chest pain, } \\
\text { hemoptysis, dyspnea }\end{array}$ & TTE & $40 \times 12$ & $\begin{array}{l}\text { ASD, PLSVC, } \\
\text { tricuspid valves } \\
\text { with severe } \\
\text { regurgitation }\end{array}$ & $\begin{array}{l}\text { Positive for } \\
\text { Staphylococcus } \\
\text { aureus }\end{array}$ & Antibiotic, surgery & Alive \\
\hline
\end{tabular}

ASD Atrial septal defect, CACSF Coronary artery-coronary sinus fistula, PLSVC Persistent left superior vena cava, RA Right atrium, TEE Transesophageal echocardiography, TTE Transthoracic echocardiography

${ }^{a}$ : measured from the figures in the literature 
Table 2 Indications for surgery of IE according to the previous studies and guidelines [22-24]

1. Patients with persistent infection who do not respond to antibiotic therapy beyond 2 weeks, except for specific pathogens that aggressive treatment should be considered early in the course of the disease (e.g. Staphylococcus aureus, Gram negative fungi); Perivalvular extension: abscesses, fistulas.

2. Patients with recurrent septic pulmonary emboli, confirmed by computed tomography pulmonary angiogram.

3. Patients with massive or worsening tricuspid regurgitation $(>2+/ 4+)$ contributing to deteriorating right (and subsequently impending left) ventricular heart failure; evaluated by echocardiography.

4. Patients in septic shock and documented right-sided IE (indication for emergency operation).

5. When the size of a vegetation increases or persists in spite of antibiotic management at $>10 \mathrm{~mm}$.

6. New-onset acute or worsening renal and/or hepatic failure.

7. Patients with right-sided IE who develop a secondary (right- or leftsided) valve endocarditis (multivalvular involvement).

8. Following failure or complications of percutaneous removal of infected intracardiac wires.

9. Complicated prosthetic valve IE: Caused by Staphylococcus aureus.

IE Infective endocarditis

\section{Additional files}

Additional file 1: Movie 1 Transthoracic echocardiography revealed the aneurysmal dilated coronary sinus with the band medium-echo mobile structure in the parasternal left ventricle long-axis view. (AVI $1089 \mathrm{~kb}$ )

Additional file 2: Movie 2 Transthoracic echocardiography revealed the band medium-echo mobile structure could be observed in the dilated coronary sinus in the modified apical 4-chamber view. (AVI $564 \mathrm{~kb}$ )

\section{Abbreviations}

ASD: Atrial septal defect; CS: Coronary sinus; IE: Infective endocarditis; TTE: Transthoracic echocardiography

\section{Funding}

Supported by the National Natural Science Foundation of China (Grant No. 81571686).

\section{Availability of data and materials}

All data is available in the manuscript.

\section{Authors' contributions}

GS drafted the manuscript and acquired the images. JZ drafted the manuscript. XZ revised the manuscript. $H Y$ acquired the echocardiography images. WH acquired the Histologic sectioning images. MD acquired the CT images. KZ acquired the surgical images. WR acquired the echocardiography images and revised the manuscript. All authors read and approved the final manuscript. All authors take responsibility for all aspects of the reliability and freedom from bias of the data presented and interpretation.

\section{Ethics approval and consent to participate}

The publication of this case report was in accordance with the Declaration of Helsinki and approved by the ethics committee of Shengjing Hospital of China Medical University.

\section{Consent for publication}

Written informed consent for the publication was obtained from the patient of this case report and any accompanying images and movies.

\section{Competing interests}

The authors declare that they have no competing interests.

\section{Publisher's Note}

Springer Nature remains neutral with regard to jurisdictional claims in published maps and institutional affiliations.

\section{Author details}

${ }^{1}$ Department of Ultrasound, Shengjing Hospital of China Medical University, Shenyang, China. ${ }^{2}$ Department of Pathology, Shengjing Hospital of China Medical University, Shenyang, China. ${ }^{3}$ Department of Radiology, Shengjing Hospital of China Medical University, Shenyang, China. ${ }^{4}$ Department of Cardiac Surgery, Shengjing Hospital of China Medical University, Shenyang, China.

Received: 27 December 2017 Accepted: 23 May 2018

Published online: 04 June 2018

\section{References}

1. Baddour LM, Wilson WR, Bayer AS, Fowler VG Jr, Tleyjeh IM, Rybak MJ, Barsic B, Lockhart PB, Gewitz MH, Levison ME, et al. Infective endocarditis in adults: diagnosis, antimicrobial therapy, and Management of Complications: a scientific statement for healthcare professionals from the American Heart Association. Circ. 2015;132(15):1435-86.

2. Correa de Sa DD, Tleyjeh IM, Anavekar NS, Schultz JC, Thomas JM, Lahr BD, Bachuwar A, Pazdernik M, Steckelberg JM, Wilson WR, et al. Epidemiological trends of infective endocarditis: a population-based study in Olmsted County, Minnesota. Mayo Clin Proc. 2010;85(5):422-6.

3. Murdoch DR, Corey GR, Hoen B, Miro JM, Fowler VG Jr, Bayer AS, Karchmer AW, Olaison L, Pappas PA, Moreillon P, et al. Clinical presentation, etiology, and outcome of infective endocarditis in the 21 st century: the international collaboration on endocarditis-prospective cohort study. Arch Intern Med. 2009;169(5):463-73.

4. Daniel WG, Mugge A, Martin RP, Lindert O, Hausmann D, Nonnast-Daniel B, Laas J, Lichtlen PR. Improvement in the diagnosis of abscesses associated with endocarditis by transesophageal echocardiography. N Engl J Med. 1991;324(12):795-800.

5. Habib G, Lancellotti P, Antunes MJ, Bongiorni MG, Casalta JP, Del Zotti F, Dulgheru R, El Khoury G, Erba PA, lung B, et al. ESC guidelines for the management of infective endocarditis: the task force for the management of infective endocarditis of the European Society of Cardiology (ESC). Endorsed by: European Association for Cardio-Thoracic Surgery (EACTS), the European Association of Nuclear Medicine (EANM). Eur Heart J 2015. 2015; 36(44):3075-128.

6. Kasravi B, Reid CL, Allen BJ. Coronary artery fistula presenting as bacterial endocarditis. J Am Soc Echocardiogr. 2004;17(12):1315-6.

7. Gill DS, Yong QW, Wong TW, Tan LK, Ng KS. Vegetation and bilateral congenital coronary artery fistulas. J Am Soc Echocardiogr. 2005;18(5):492-3.

8. Kwan C, Chen O, Radionova S, Sadiq A, Moskovits M. Echocardiography: a case of coronary sinus endocarditis. Echocardiogr. 2014;31(9):E287-8.

9. Takashima A, Yagi S, Yamaguchi K, Takagi E, Kanbara T, Ogawa H, Ise T, Kusunose K, Tobiume T, Yamada H, et al. Vegetation in the coronary sinus that concealed the presence of a coronary arteriovenous fistula in a patient with infectious endocarditis. Int J Cardiol. 2016;207:266-8.

10. Kumar KR, Haider S, Sood A, Mahmoud KA, Mostafa A, Afonso LC, Kottam AR. Right-sided endocarditis: eustachian valve and coronary sinus involvement. Echocardiogr. 2017;34(1):143-4.

11. Theodoropoulos KC, Papachristidis A, Walker N, Dworakowski R, Monaghan MJ. Coronary sinus endocarditis due to tricuspid regurgitation jet lesion. Eur Heart J Cardiovasc Imaging. 2017;18(3):382.

12. Habib G, Badano L, Tribouilloy C, Vilacosta I, Zamorano JL, Galderisi M, Voigt JU, Sicari R, Cosyns B, Fox K, et al. Recommendations for the practice of echocardiography in infective endocarditis. Eur J Echocardiogr. 2010;11(2):202-19.

13. Durack DT, Lukes AS, Bright DK. New criteria for diagnosis of infective endocarditis: utilization of specific echocardiographic findings. Duke Endocarditis Service. Am J Med. 1994;96(3):200-9.

14. Cahill TJ, Prendergast BD. Infective endocarditis. Lancet. 2016; 387(10021):882-93.

15. Frontera JA, Gradon JD. Right-side endocarditis in injection drug users: review of proposed mechanisms of pathogenesis. Clin Infect Dis. 2000;30(2):374-9. 
16. Lee MR, Chang SA, Choi SH, Lee GY, Kim EK, Peck KR, Park SW. Clinical features of right-sided infective endocarditis occurring in non-drug users. J Korean Med Sci. 2014;29(6):776-81.

17. Fowler VG Jr, Miro JM, Hoen B, Cabell CH, Abrutyn E, Rubinstein E, Corey GR, Spelman D, Bradley SF, Barsic B, et al. Staphylococcus aureus endocarditis: a consequence of medical progress. Jama. 2005;293(24):3012-21.

18. Moon MR, Stinson EB, Miller DC. Surgical treatment of endocarditis. Prog Cardiovasc Dis. 1997;40(3):239-64.

19. Lowes JA, Hamer J, Williams G, Houang E, Tabaqchali S, Shaw EJ, Hill IM, Rees GM. 10 years of infective endocarditis at St. Bartholomew's hospital: analysis of clinical features and treatment in relation to prognosis and mortality. Lancet. 1980;1(8160):133-6.

20. Lamas CC, Eykyn SJ. Blood culture negative endocarditis: analysis of 63 cases presenting over 25 years. Heart. 2003;89(3):258-62.

21. Prendergast BD, Tornos P. Surgery for infective endocarditis: who and when? Circ. 2010;121(9):1141-52.

22. Gutierrez-Martin MA, Galvez-Aceval J, Araji OA. Indications for surgery and operative techniques in infective endocarditis in the present day. Infect Disord Drug Targets. 2010;10(1):32-46.

23. Akinosoglou K, Apostolakis E, Koutsogiannis N, Leivaditis V, Gogos CA. Rightsided infective endocarditis: surgical management. Eur J Cardio-thorac Surg. 2012:42(3):470-9.

24. Gould FK, Denning DW, Elliott TS, Foweraker J, Perry JD, Prendergast BD, Sandoe JA, Spry MJ, Watkin RW. Working Party of the British Society for antimicrobial C: guidelines for the diagnosis and antibiotic treatment of endocarditis in adults: a report of the working Party of the British Society for antimicrobial chemotherapy. J Antimicrob Chemother. 2012;67(2):269-89.

25. Pang PY, Sin YK, Lim CH, Tan TE, Lim SL, Chao VT, Chua YL. Surgical management of infective endocarditis: an analysis of early and late outcomes. Eur J Cardio-thorac Surg. 2015;47(5):826-32.

26. Ortiz C, Lopez J, Garcia H, Sevilla T, Revilla A, Vilacosta I, Sarria C, Olmos C, Ferrera C, Garcia PE, et al. Clinical classification and prognosis of isolated right-sided infective endocarditis. Med. 2014;93(27):e137.

27. Wang TK, Oh T, Voss J, Pemberton J. Characteristics and outcomes for right heart endocarditis: six-year cohort study. Heart, Lung Circ. 2014:23(7):625-7.

28. Gaca JG, Sheng S, Daneshmand M, Rankin JS, Williams ML, O'Brien SM, Gammie JS. Current outcomes for tricuspid valve infective endocarditis surgery in North America. Ann Thorac Surg. 2013;96(4):1374-81.

\section{Ready to submit your research? Choose BMC and benefit from}

- fast, convenient online submission

- thorough peer review by experienced researchers in your field

- rapid publication on acceptance

- support for research data, including large and complex data types

- gold Open Access which fosters wider collaboration and increased citations - maximum visibility for your research: over $100 \mathrm{M}$ website views per year

At BMC, research is always in progress.

Learn more biomedcentral.com/submissions 